\title{
PROVAS DE ATIVIDADE INFLAMATÓRIA NO PÊNFIGO FOLIÁCEO ENDÊMICO
}

\author{
João Franquini Junior, Sheila Jorge Adad, Ariadna Helena Cândido Murta, \\ Cesar Augusto de Morais, Vicente de Paula Antunes Teixeira e Virmondes \\ Rodrigues Junior
}

\begin{abstract}
$O$ pênfigo foliáceo endêmico (PFE) é una afecção onde fenômenos auto-imunes são frequentemente relacionados com sua patogênese. Abordaram-se neste estudo, alguns testes laboratoriais freqüentemente alterados em outras doenças auto-imunes. Foram estudados em 20 pacientes com $P F E$ a presença ou alterações de fator antinúcleo (FAN), fator reumatóide (FR), proteína C-reativa (PCR), velocidade de hemossedimentação (VHS), eletroforese de proteinas e o número total de leucócitos. Encontrou-se PCR positiva em mais de $65 \%$ dos casos, leucocitose moderada na maioria dos pacientes, VHS aumentada e alterações discretas da análise de proteinas do sangue. O FAN e o FR apresentaram-se negativos em todos os casos. Embora estes exames sejam considerados inespecíficos, o seu estudo associado ao quadro clínico pode colaborar no acompanhamento do PFE.
\end{abstract}

Palavras-chaves: Pênfigo foliáceo endêmico. Doença auto-imune. Provas at atividade inflamatória. Dermatites bolhosas.

O pênfigo é uma doença que envolve pele e mucosas, sendo caracterizada por bolhas intraepidérmicas e presença de anticorpos da classe IgG dirigidos contra uma glicoproteína associada ao desmossoma, chamada desmogleína $\mathrm{I}^{10}$.

Dependendo do nível de localização das lesões na epiderme, o pênfigo pode ser classificado basicamente em formas superficiais (foliáceo e eritematoso) quando as bolhas surgem abaixo do estrato córneo e formas profundas (vulgar e vegetante) se as bolhas surgirem em camadas mais profundas da epiderme, ou seja, em posição suprabasal $^{29}$.

Algumas vezes encontram-se em pacientes com doença bolhosa crônica, algumas doenças autoimunes do tecido conjuntivo, como miastenia grave, lupus eritematoso sistêmico, esclerose sistêmica progressiva e doenças neoplásicas tais como: timoma, linfoma ou carcinoma epidermóide. Freqüentemente, encontram-se nessas doenças auto-

Laboratório de Imunologia da Faculdade de Medicina do Triângulo Mineiro, Uberaba, MG.

Auxílio financeiro: Fundação de Ensino e Pesquisa de Uberaba e PIBIC/CNPq.

Endereça para correspondencia: Dr. Virmondes Rodrigues J.

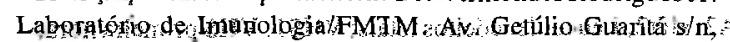
38025-400 Uberaba, MG, Brasil.

Recebido para publicação em $05 / 03 / 93$. imunes, anticorpos não órgão-específicos, especialmente anticorpos antinucleares (FAN) ${ }^{14}$.

Em outras condições, especialmente na artrite reumatóide, é freqüente o achado laboratorial de fator reumatóide (FR), uma classe de anticorpo anti-imunọglobulina, embora ainda não se saiba ao certo sua importância nas doenças em que é encontrado ${ }^{3}$.

Outra contribuição para a avaliação das doenças do tecido conjuntivo é o estudo das proteínas de fase aguda encontradas no sangue e que refletem a presença e o grau de inflamação. O estudo apresentase útil ainda, no estabelecimento da terapêutica, pois sua cóncentração sérica reflete a atividade da doença ${ }^{312}$.

Neste trabalho, procuraram-se algumas alterações bioquímicas em pacientes com pênfigo foliáceo endêmico (fogo selvagem) na tentativa de identificar algum traço comparativo com outras doenças auto-imunes, tais como as doenças do tecido conjuntivo. Dessa forma, foram pesquisados o FAN, o FR, a proteína C-reativa (PCR) e as características da velocidade de hemossedimentação (VHS), da eletroforese de proteínas e o número total de léucócitos, en pacientes com pênifigo foliấcéo

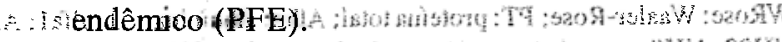

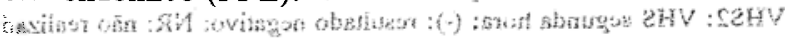

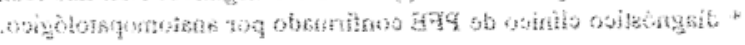


Franquini Junior J, Adad SJ, Murta AHC, Morais CA, Teixeira VPA, Rodrigues Junior V. Provas de atividade inflamatória no pênfigo foliáceo endêmico. Revista da Sociedade Brasileira de Medicina Tropical 27:25-29, janmar, 1994.

\section{MATERIAL E MÉTODOS}

Num período de nove meses foram coletadas amostras sanguíneas de 20 pacientes do Hospital do Pênfigo em Uberaba, de ambos os sexos, com idades entre 9 e 68 anos. O diagnóstico de PFE foi obtido com base em critérios clínicoepidemiológicos, realizando-se em dez pacientes estudo anatomopatológico e imunofluorescência direta. Todos os pacientes incluídos neste estudo apresentavam-se em fase de atividade clínica da doença e a maioria em uso de corticosteróide sistêmico no momento da coleta da amostra sanguínea. Quatro pacientes apresentaram melhora clínica com remissão das lesões, sendo colhida uma segunda amostra nessa ocasião.

Quanto à intensidade da doença, foram classificadas em formas localizadas, quando apresentavam lesões restritas a membros ou face, $e$ disseminadas quando se distribuiam de forma difusa por todo o corpo.

Os soros obtidos por centrifugação foram aliquotados e armazenados a $-70^{\circ} \mathrm{C}$ até que fossem testados.

O teste para deteç̧ão de FAN foi realizado em imprints de fígado de rato e revelado com conjugado anti-IgG fluoresceinado.

Para a detecção do FR foi utilizado o teste de fixação do látex que contém partículas de látex adsorvidas com gama-globulina, sendo portanto, aglutinadas na presença de FR (Kit Biolab; ArtriSlidex). Foi também usado o teste de Waaler-Rose, o qual usa hemácias de carneiro sensibilizadas com anticorpos de coelho anti-hemácias de carneiro, que aglutinam na presença de FR. É o teste mais específico para detecção do $\mathrm{FR}^{3}$.

A pesquisa de PCR foi realizada por teste de látex em lâmina, segundo Kit da Biolab (PCR slidex com sensibilidade de $7 \pm 1 \mathrm{mg} / \mathrm{l}$ ).

A eletroforese de proteínas foi realizada em acetato de celulose e a leitura da fita, em Densitômetro Integrador automático de eletroforese (Tecnow Argos 7). A dosagem de proteína total foi realizada em aparelho automatizado (Cobas Mira - Roche).

A VHS foi feita segundo método de Westergren, em pipeta graduada em milímetros, com leituras aos 60 e 120 minutos ${ }^{7}$. A mesma amostra sanguínea usada para a VHS, coletada em frasco Vacutainer com EDTA (Etileno-diaminotetra-acético), foi também usada para contagem de leucócitos totais, feita em Coulter $T$ 890, com capacidade parcial de diferenciação celular.

\section{RESULTADOS}

Os resultados apresentados nas Tabelas 1 e 2, apontam para uma leucocitose observada em 17 (85\%) pacientes.

Tabela 1 - Provas de atividade inflamatória em pacientes com PFE em fase aguda.

\begin{tabular}{|c|c|c|c|c|c|c|c|c|c|c|c|c|c|c|}
\hline Paciente & $\begin{array}{c}\text { Idade } \\
\text { anos }\end{array}$ & Látex & WRose & $\begin{array}{l}\mathrm{PCR} \\
\mathrm{mg} / 1\end{array}$ & FAN & $\begin{array}{l}\text { PT } \\
\mathrm{g} / \mathrm{dl}\end{array}$ & $\begin{array}{l}\text { Albu } \\
\mathrm{g} / \mathrm{dl}\end{array}$ & $\begin{array}{c}\mathrm{Al} \\
\mathrm{g} / \mathrm{d} l\end{array}$ & $\begin{array}{l}\mathrm{A} 2 \\
\mathrm{~g} / \mathrm{dl}\end{array}$ & $\begin{array}{l}\text { Beta } \\
\mathrm{g} / \mathrm{dl}\end{array}$ & $\begin{array}{c}\text { Gama } \\
\mathrm{g} / \mathrm{d} \mathrm{l}\end{array}$ & $\begin{array}{c}\text { Leuco } \\
\mathrm{mm} 3\end{array}$ & $\begin{array}{c}\text { VHS1 } \\
\mathrm{mm}\end{array}$ & $\begin{array}{c}\text { VHS2 } \\
\text { mm }\end{array}$ \\
\hline 2A AVP & 32 & - & - & - & - & 6,7 & 4,29 & 0,20 & 0,33 & 0,60 & 1,27 & 7300 & NR & NR \\
\hline 4A LCJS* & 12 & - & - & 7 & - & 7,1 & 3,48 & 0,07 & 0,64 & 0,64 & 2,27 & 16200 & NR & NR \\
\hline $6 \mathrm{~A} \mathrm{MAA} *$ & 9 & - & - & 7 & - & 6,5 & 3,77 & 0,13 & 0,45 & 0,39 & 1,75 & 16800 & NR & NR \\
\hline 7A JF* & 36 & - & - & - & - & 8,5 & 5,27 & 0,25 & 0,85 & 1,10 & 1,02 & 15900 & NR & NR \\
\hline 8A DPSS ${ }^{*}$ & 35 & - & - & 200 & - & 8,8 & 4,31 & 0,09 & 0,62 & 1,14 & 2,64 & 14400 & NR & NR \\
\hline $12 \mathrm{~A} V \mathrm{~F}^{*}$ & 26 & - & - & - & - & 7,6 & 3,65 & 0,38 & 0,80 & 0,68 & 2,13 & 13900 & NR & NR \\
\hline 17A VSS & 59 & - & - & 200 & - & 8,1 & 4,37 & 0,16 & 0,81 & 1,05 & 1,70 & 12500 & NR & NR \\
\hline $18 \mathrm{~A} \mathrm{FM*}$ & 43 & - & - & 200 & - & 8,0 & 3,68 & 0,40 & 0,72 & 0,80 & 2,40 & 15100 & NR & NR \\
\hline $19 \mathrm{~A}$ AAM & 46 & - & - & - & - & 8,3 & 4,07 & 0,24 & 0,74 & 1,32 & 1,90 & 7500 & NR & NR \\
\hline 20A VBM & 68 & - & - & - & - & 7,9 & 4,98 & 0,08 & 0,63 & 0,63 & 1,58 & 15400 & NR & NR \\
\hline 24A CRL* & 15 & - & - & 200 & - & 7,3 & 2,63 & 0,37 & 0,95 & 1,02 & 2,33 & 21900 & NR & NR \\
\hline 25A DBSB & 18 & - & - & - & - & 6,5 & 4,03 & 0,26 & 0,39 & 0,65 & 1,17 & 20700 & 50 & 87 \\
\hline 26A HFG & 18 & - & - & - & - & 8,1 & 2,99 & 0,40 & 0,90 & 1,13 & 2,67 & 15400 & 70 & 90 \\
\hline 28A CEA & 26 & - & - & 200 & - & 6,5 & 3,64 & 0,13 & 0,65 & 0,78 & 1,30 & 16800 & 65 & 90 \\
\hline $29 \mathrm{~A} J \mathrm{JT}$ & 17 & - & - & 200 & - & 6,2 & 3,16 & 0,06 & 0,66 & 0,74 & 1,55 & 14800 & 60 & 90 \\
\hline 30A ESP & 13 & - & - & 200 & - & 5,4 & 2,86 & 0,27 & 0,76 & 0,70 & 0,81 & 27200 & 72 & 110 \\
\hline
\end{tabular}

WRose: Waaler-Rose; PT: proteína total; Albu: albumina; A1 : alfa 1; A2: alfa2; Leuco: leucócitos totais; VHS1: VHS primeira hora; VHS2: VHS segunda hora; (a): resultado negátivo; NR: nāo reálizado.

* diagnóstico clínico de PFE confirmado por anatomopatológico. 
Franquini Junior J, Adad SJ, Murta AHC, Morais CA, Teixeira VPA, Rodrigues Junior V. Provas de atividade inflamatória no pênfigo foliáceo endêmico. Revista da Sọciedade Brasileira de Medicina Tropical 27:25-29, janmar, 1994.

Tabela 2 - Provas de atividade infiamatória em pacientes com PFE na fase ativa (A) e fase de melhora clínica (B).

\begin{tabular}{|c|c|c|c|c|c|c|c|c|c|c|c|c|c|c|}
\hline Paciente & $\begin{array}{c}\text { Idade } \\
\text { anos }\end{array}$ & Látex & WRose & $\begin{array}{l}\text { PCR } \\
\mathrm{mg} / 1\end{array}$ & FAN & $\begin{array}{l}\text { PT } \\
\mathrm{g} / \mathrm{dl}\end{array}$ & $\begin{array}{l}\text { Albu } \\
\text { g/dl }\end{array}$ & $\begin{array}{l}\mathrm{A} 1 \\
\mathrm{~g} / \mathrm{dl}\end{array}$ & $\begin{array}{l}\mathrm{A} 2 \\
\mathrm{~g} / \mathrm{dl}\end{array}$ & $\begin{array}{l}\text { Beta } \\
\text { g/dl }\end{array}$ & $\begin{array}{c}\text { Gama } \\
\mathrm{g} / \mathrm{d} l\end{array}$ & $\begin{array}{l}\text { Leuco } \\
\mathrm{mm} 3\end{array}$ & $\begin{array}{c}\text { VHS1 } \\
\mathrm{mm}\end{array}$ & $\begin{array}{c}\text { VHS2 } \\
\text { mm }\end{array}$ \\
\hline 1A GRB & 16 & - & - & 200 & - & 6,4 & 3,33 & 0,06 & 0,45 & 0,58 & 1,98 & 10400 & NR & NR \\
\hline $1 \mathrm{~B}$ GRB & 16 & - & - & - & - & 6,9 & 4,21 & 0,07 & 0,41 & 0,55 & 1,66 & 12400 & NR & NR \\
\hline $3 \mathrm{~A} W S S$ & 14 & - & . & 200 & - & 6,2 & 2,91 & 0,19 & 0,93 & 0,56 & 1,61 & 14400 & NR & NR \\
\hline 3B WSS & 14 & - & - & - & - & 7,9 & 5,37 & 0,32 & 0,47 & 0,55 & 1,18 & 19300 & NR & NR \\
\hline $10 \mathrm{~A} \mathrm{IFC}^{*}$ & 15 & - & - & - & - & 8,6 & 3,44 & 0,43 & 0,69 & 0,69 & 3,35 & 18100 & NR & NR \\
\hline 10B IFC & 15 & - & - & - & - & 6,9 & 5,11 & 0,07 & 0,21 & 0,48 & 1,03 & 14500 & 26 & 52 \\
\hline 22A MADB* & $* 45$ & - & - & 200 & - & 6,2 & 2,23 & 0,12 & 0,62 & 0,68 & 2,54 & 14700 & NR & NR \\
\hline 22B MADB & 45 & - & - & 7 & - & 7,4 & 3,70 & 0,22 & 0,59 & 0,88 & 1,99 & 12900 & 40 & 73 \\
\hline
\end{tabular}

Paciente: (A) $1^{\text {a }}$ coleta (B) $2^{a}$ coleta, em fase de inatividade

WRose: Waaler-Rose; PT: proteina total; Albu: albumina; A1: alfa 1; A2: alfa2; Leuco: leucócitos totais; VHS1: VHS primeira hora; VHS2: VHS segunda hora; $(-)$; resultado negativo; NR: não realizado.

* diagnóstico clínico de PFE confirmado por anatomopatológico.

O paciente 1A GRB não estava em uso de corticóide no momento da coleta de sangue.

A PCR estava presente em $12(60 \%)$ casos. Em quatro casos onde uma segunda amostra foi coletada após melhora das lesões (Tabela 2), notou-se negativação da mesma em dois casos e diminuição em um caso.

A pesquisa do FAN e FR por aglutinação em látex e Waaler-Rose, mostrou-se negativa em todos os casos.

A eletroforese de proteínas séricas apresentou hipoalbuminemia em nove $(45 \%)$ pacientes e aumento da fração de gama-globulina em 14 (70\%) casos. De modo semelhante à PCR, nos quatro casos em que uma segunda amostra foi colhida, observou-se normalização em dois deles e nítida diminuição dos níveis da fração gama em outros dois, quando comparados à amostra inicial.

Nos casos em que foi realizado VHS, a mesma apresentou-se elevada em todos os pacientes.

\section{DISCUSSÃO}

Auto-anticorpos Anti-SSA-Ro são comumente encontrados em pacientes com lupus eritematoso, síndrome de Sjögren, esclerose sistêmica e raramente, artrite reumatóide 4 . Usando técnicas de imunodifusão dupla com preparações antigênicas de extrato de baço bovino, alguns autores não encontraram a associação desses anticorpos ou fatores antinucleares (FAN) com o pênfigo foliáceo endêmico ${ }^{13}$. Por outro lado, Deng e cols ${ }^{4}$ usando métodos mais sensíveis como ELISA e análise por immunoblot, detectaram anti-SSA-Ro em aproximadamente $10 \%$ dos pacientes com pênfigo, enquanto o FAN foi positivo em $20 \%$ dos pacientes. A importância do achado desses anticorpos não órgão-específicos em pacientes com pênfigo permanece desconhecida, ainda que estes pacientes não apresentem sinais ou sintomas que sugiram doença do tecido conjuntivo. O fato de não se detectar FAN em nenhum dos pacientes deste estudo está de acordo como observado em outros trabalhos ${ }^{1}$ 13 , embora possa ser devido à corticoterapia ou à metodologia usada ser menos sensível ${ }^{4}$.

O fator reumatóide (FR) é constituído por imunoglobulinas com especificidade para o fragmento $\mathrm{Fc}$ da IgG e está presente em mais de $75 \%$ dos pacientes com artrite reumatóide, pacientes com lupus eritematoso (30\%), síndrome de Sjögren $(90 \%)$, e menos freqüentemente na esclerodermia, polimiosite e condições inflamatórias crônicas ${ }^{14}$.

Neste estudo, não se detectou a presença de FR, utilizando-se técnicas com maior sensibilidade (látex) e maior especificidade (Waaler-Rose).

Durante processos inflamatórios, a concentração sérica de certas proteínas, chamadas proteínas de fase aguda, encontra-se aumentada. Uma destas proteínas é a PCR, assim chamada por se ligar à proteína $\mathrm{C}$ do pneumococo ${ }^{14}$. A sua presença em diversas enfermidades, em geral, tende a seguir de forma paralela ao aumento da VHS, que se mostra aumentada também durante processos inflamatórios e outras condições ${ }^{11}$. 
Franquini Junior J, Adad SJ, Murta AHC, Morais CA, Teixeira VPA, Rodrigues Junior V. Provas de atividade inflamatória no pênfigo foliáceo endêmico. Revista da Sociedade Brasileira de Medicina Tropical 27:25-29, janmar, 1994.

Segundo alguns autores, os corticosteróides, mesmo em baixas doses, podem suprimir a $\mathrm{PCR}^{3}$. Neste estudo, a PCR foi positiva em $60 \%$ dos casos, assemelhando-se ao relato de $85 \%$ descrito por outros autores ${ }^{5}$, embora sem especificação de terapêutica. $O$ fato de apresentar-se negativa em alguns pacientes pode ser atribuído ao uso de corticosteróides. Contudo já foi descritoem pacientes submetidos à corticoterapia, a negativação da PCR apenas quando há remissão clínica completa ${ }^{5}$. Em 3 casos onde a primeira amostra foi coletada antes ou no início da corticoterapia e uma segunda coleta na fase de inatividade da doença (pacientes 1, 3 e 22) houve negativação do teste em dois pacientes (pacientes 1 e 3) e queda do título de 200 para 7 em outro. Este achado poderia ser explicado pela própria inatividade da doença ou pelo uso do corticóide.

A VHS sofre alterações sempre que existe um desequilíbrio humoral comprometendo as proteínas plasmáticas, acelerando-se quando aumenta a produção de fibrinogênio ou globulinas. É uma prova inespecífica e de resultados inconstantes, sofrendo alterações na presença de lesões orgânicas ativas $^{12}$. A VHS realizada em parte dos pacientes estudados, mostrou-se aumentada naqueles em fase ativa. Em dois pacientes que estavam em fase de remissão das lesões, a VHS estava aumentada, porém em níveis inferiores àqueles em fase de lesão.

O estudo do fracionamento de proteínas séricas, mostrou hipoalbuminemia em $45 \%$ dos casos e hipergamaglobulinemia em $70 \%$ dos pacientes. Outros autores ${ }^{6}$, encontraram as mesmas alterações de comportamento das frações protéicas, presentes em 100\% de um grupo de 23 pacientes estudados. Nos quatro casos em que foi coletada segunda amostra na fase de melhora clínica, houve normalização (dois casos) e aumento de albumina (dois casos). O único caso de hipoproteinemia (paciente 30A), foi de uma paciente em fase ativa $\mathrm{e}$ inicial da doença, sendo também a que apresentou maior área de superfície corporal acometida. As extensas áreas desnudas e com bolhas podem portanto explicar a perda protéica desta paciente, que se fez de forma não seletiva.

A observação da leucocitose moderada na maioria dos pacientes, apresenta-se de difícil análise, pois o próprio uso de corticóide pode estar contribuindo para esta alteração ${ }^{8}$. Por outro lado, o fato de muitos pacientes apresentarem episódios freqüentes de piodermites, pode ser levado em consideração como estímulo à leucocitose.

O presente estudo mostra que alguns parâmetros de avaliação de atividade de doenças auto-imunes estavam pouco alterados, exceto a PCR, VHS e fracionamento de proteínas séricas no PFE. Por outro lado, estas provas de atividade inflamatória tomadas em conjunto com o exame clínico, podem auxiliar no acompanhamento do PFE.

\section{SUMMARY}

Endemic pemphigus foliaceus (EPF) has its pathogenesis frequently associated to autoimmune phenomena. In this paper, a few routine laboratory tests, usually disturbed in some autoimmune diseases, were taken in 20 patients with EPF, which were screened for antinuclear antibodies (ANA), rheumatoid factor (RF), $C$-reactive protein (CRP) and changes of eritrocyte sedimentation rate (ESR), serologic proteins electrophoresis and total leucocyte count. The CRP was found in $60 \%$ of cases, leucocitosis in $85 \%$, high ESR in all of them and mild alterations in serologic proteins analysis. No ANA or RF was found. Although widely accepted as inespecific tests, we believe that an association of the laboratory routine tests with clinical findings, can prove to be helpful in the follow up care of these patients.

Key-words: Endemic pemphigus foliaceus. Autoimmune disease. Tests of inflamatory activity. Bullous diseases.

\section{AGRADECIMENTOS}

Ao Prof. Mário León Silva-Vergara pela revisão e críticas no preparo do manuscrito e ao Dr. João Eduardo Caixeta pela exérese do material para biópsia.

\section{REFERÊNCIAS BIBLIOGRÁFICAS}

1. Ahmed AR. Absence of anti-Ro and anti-La antibodies in pemphigus and pemphigoid sera. Archives of Dermatological Research 280:127-128, 1988.

2. Ahmed AR, Graham J, Jordon RE, Provost TT. Pemphigus, current concepts. Annals of Internal 
Franquini Junior J, Adad SJ, Murta AHC, Morais CA, Teixeira VPA, Rodrigues Junior V. Provas de atividade inflamatória no pênfigo foliáceo endêmico. Revista da Sociedade Brasileira de Medicina Tropical 27:25-29, janmar, 1994.

Medicine 92:396-405, 1980.

3. Baum J, Ziff M. Hallazgos de laboratorio en la artritis reumatoidea. $l n$ : McCarty DJ (ed) Artritis y otras patologias relacionadas, $10^{\mathrm{a}}$ edicion, Editorial Médica Panamericana SA, Buenos Aires p.656673, 1987.

4. Deng IS, Lee PYP, Fratto JL. Significance and specificity of anti-SSA/Ro antibody in patients with bullous disorders. International Archives of Allergy and Applied Immunology 92:323-327, 1990.

5. Furtado TA, Cardoso JP, Cisalpino EO. A proteina $\mathrm{C}$ reativa no pênfigo foliáceo. O Hospital 58:157$162,1960$.

6. Furtado TA, Rodrigues BA. Paper electrophoresis of serum proteins in pemphigus foliaceus. Journal of Investigative Dermatology 33:227-229, 1959.

7. Goldenberg J, Atra E. Provas de atividade inflamatória. In: Guimarães RX, Campos Guerra CC (eds) Clínica e laboratório: interpretação clínica das provas laboratoriais, $3^{a}$ edição, Sarvier, São Paulo p.435-440, 1983.

8. Haynes RC, Larner J. Hormônio corticotrópico supra-renal. In: Goodman LS, Guilman A (eds) As bases farmacológicas da terapêutica, $5^{\mathrm{a}}$ edição, Guanabara Koogan SA, Rio de Janeiro p.13071338, 1978.
9. Korman N. Pemphigus. Journal of the American Academy of Dermatology 18:1219-1238, 1988.

10. Korman NJ, Eyre RW, Klaus-Kovtun V, Stanley JR. Demonstration of an adhering-junction molecule (plakoglobin) in the autoantigens of pemphigus foliaceus and pemphigus vulgaris. The New England Journal of Medicine 321:631-635, 1989.

11. McEwen $C$, Ziff $M$. Basic sciences in relation to rheumatic diseases. Medical Clinics of North America 39:765-782, 1955.

12. Miller $O$. Diagnóstico bacteriológico e imunobiológico. 3.Provas sorológicas nas doenças reumáticas. In: Miller $\mathrm{O}$ (ed) Laboratório para o Clínico, $7^{a}$ edição, Livraria Atheneu Editora, Rio de Janeiro p.139-151, 1991.

13. Squiquera HL, Diaz LA, Sampaio SAP, Rivitti EA, Martins CR, Cunha PR, Lombardi C, Lavrado C, Borges P, Friedman H, Labib RS, Anhalt GJ. Serologic abnormalities in patients with endemic pemphigus foliaceus (fogo selvagem), their relatives, and normal donors from endemic and non-endemic areas of Brazil. The Journal of Investigative Dermatology 91:189-191, 1988.

14. Stites DP, Terr AI. Basic and Clinical Immunology. 7th edition, Appleton \& Lange, Connecticut, 1991. 